University of California, Hastings College of the Law UC Hastings Scholarship Repository

Faculty Scholarship

2006

\title{
Description and Evaluation of an Interprofessional Patient Safety Course for Health Professions and Related Sciences Students
}

Debra Gerardi

UC Hastings College of the Law, gerardig@uchastings.edu

Follow this and additional works at: https://repository.uchastings.edu/faculty_scholarship

\section{Recommended Citation}

Debra Gerardi, Description and Evaluation of an Interprofessional Patient Safety Course for Health Professions and Related Sciences Students, 2 J. Patient Safty 207 (2006).

Available at: https://repository.uchastings.edu/faculty_scholarship/1621

This Article is brought to you for free and open access by UC Hastings Scholarship Repository. It has been accepted for inclusion in Faculty Scholarship by an authorized administrator of UC Hastings Scholarship Repository. 


\title{
Description and Evaluation of an Interprofessional Patient Safety Course for Health Professions and Related Sciences Students
}

\author{
Kimberly A. Galt, PharmD,*† Karen A. Paschal, PT, MS, *†* Richard L. O’Brien, MD, $\$ / /$ \\ Robert J. McQuillan, MD, ***I Janet K. Graves, RN, PhD, $\dagger \dagger$ Barbara Harris, PhD, MSW, $+*$ \\ Catherine Mahern, JD, $\S \S$ Linda S. Scheirton, PhD, †//I James D. Bramble, PhD, * $+\mathbb{I}$ \\ Bartholomew E. Clark, PhD, *† John M. Gleason, DBA, *** Pat Hoidal, RN, MPH, $/ / \dagger+\dagger$ \\ Kevin Moores, PharmD, $+\neq+$ Keli Mu, PhD, OT, ${ }^{*} \$ \xi \oint$ Ann M. Rule, PharmD, ${ }^{\dagger}$ \\ J. Chris Bradberry, PharmD, $\dagger$ Roberta Sonnino, MD,** and Debra Gerardi, BSN, JD, MPHIप
}

\begin{abstract}
Objectives: The structure, process, and outcomes associated with planning, developing, and offering an interprofessional course on the foundations of patient safety is described, including how organizational, structural, cultural, and attitudinal barriers were overcome. Methods: Seventeen faculty members from 7 colleges and schools and medical center participated - from the fields of decision sciences and systems, dentistry, medicine, law, nursing, occupational therapy, pharmacy, physical therapy, social work, health care administration, and outcomes management in health systems. Student assessment included theme analysis of open-ended questions, descriptive analysis of multiple- response option questionnaires, and criterionbased assessment of student performance on case studies. Triangulation of student comments, final course evaluation, and student performance evaluations were performed to learn overarching themes of student experience with the course.

Results: The students learned a different way of thinking, found the instructional design and active learning methods useful to learning, and felt prepared to solve problems in the future. Students believed that the content was an essential core knowledge for all health professionals (87\%) and should be required for all health professions students (78\%). Students achieved an application level of learning (77\%) within the cognitive domain and the valuing level within the affective domain. Students agree (96\%) that they can define and
\end{abstract}

From the ${ }^{*}$ Creighton Health Services Research Program, †School of Pharmacy and Health Professions; †Clinical Experiential Education, §Office of Interprofessional Education, Office of the Vice President for Health Sciences, $\|$ Creighton University Medical Center, $\mid$ Department of Anesthesiology, **School of Medicine, ††School of Nursing, ††School of Literature, Sciences and the Arts, $\S \S$ School of Law, ||||Department of Occupational Therapy, $\mathbf{q}$ Health Services Administration Certificate Program, ***Department of Information Systems and Technology, College of Business Administration, $\dagger \dagger \dagger$ Clinical Process Improvement, †t Drug Information Services, $\S \S \S$ Department of Occupational Therapy, and $9 \uparrow \uparrow$ Werner Institute for Negotiation and Dispute Resolution, Creighton University, Omaha, Nebraska.

Correspondence: Kimberly A. Galt, PharmD, Creighton Health Services Research Program, School of Pharmacy and Health Professions, Creighton University, 2500 California Plaza, Boyne Room 143, Omaha, NE 68178 (e-mail: kgalt@creighton.edu).

Copyright (C) 2006 by Lippincott Williams \& Wilkins apply the basic principles and tenets of patient safety, including identification of tools needed to work effectively within the health system and to improve safety and strongly agree (100\%) that they value patient safety as a professional practice framework.

Conclusion: The universitywide implementation case may offer important lessons to others nationally in health care education.

Key Words: patient safety, interprofessional education, educational outcomes, performance assessment, patient safety curriculum, decision sciences and systems, dentistry, medicine, law, nursing, occupational therapy, pharmacy, physical therapy, social work, health care administration, outcomes management in health systems

( $J$ Patient Saf 2006;2:207-216)

T he importance of improving patient safety in health care has become a societal imperative since the sentinel report, "To Err is Human," was published by the Institute of Medicine in 2000. ${ }^{1}$ Substantial public and private monies have been invested in the science of safety and the translation of new discoveries into practice. Furthermore, there has been significant investment in educating the wide range of stakeholders in patient safety, including health professionals.

Much of the science of safety builds on the recognition that patient harm occurs secondary to errors resulting from system problems and failures. Systems have both technical and human components, and understanding this interface is essential for systems improvement to reduce errors. Solving complex system problems requires that all health professions have adequate understanding of the science of safety and its translation into practice. At present, it is an uncommon framework in health professions education to deliver core content related to the fundamental science and application of safety principles.

The complexity of health care systems and the necessary involvement and communication of different health professions in the care of individual patients necessitate an interprofessional approach to the use of patient safety science to achieve improvements. Similar to the discipline of study of 
patient safety, it is uncommon to find interprofessional education in the health professions. At present, this might be observed in the clinical experience component of education when students go to health care delivery environments simultaneously to learn the professional skills application and practice these efforts. The extent of interprofessional engagement in these experiences varies from almost nonexistent to purposefully structured. There are no governing modes of adoption.

A national imperative has called for the health professions to restructure professional education to emphasize patient-centered learning through interprofessional teamwork. This was recently articulated by the release of the Institute of Medicine Report on patient-centered and interprofessional education entitled "Health Professions Education: A Bridge to Quality". 2 The report identified core competencies that all health professions should possess and urges training programs to adopt and address these core competencies.

It is our belief that to achieve successful interprofessional practices among health professionals, we must begin in the classroom and in preclinical components of education. Our educational culture must promote interprofessional understanding and learning through early engagement of faculty and students in relevant areas of learning. We also believe that the teaching of foundations knowledge related to patient safety is an essential content area for all health professionals and that all health professionals should share a basic common knowledge of this area. This paper describes the structure, process, and outcomes associated with the successful development and offering of a didactic course designed on these premises, entitled "Interprofessional Education 410: Foundations in Patient Safety."

\section{METHODS}

\section{Formation of Course Leadership and Faculty Core}

A team on patient safety curriculum was convened by the Office of Interprofessional Education in the winter of 2003 to evaluate the potential for and the development of a universitywide interprofessional course about patient safety.
The faculty leader selected to chair the committee (primary author) is a professor in the School of Pharmacy and Health Professions and has a track record of expertise in research, practice, and education related to both patient safety and interprofessional work. Faculty from a campuswide representation of disciplines important to the broad aspects of fundamental knowledge in patient safety were invited to participate. A total of 17 faculty members representing decision sciences and systems, dentistry, medicine, law, nursing, occupational therapy, pharmacy, health administration, physical therapy, and social work from 7 colleges and schools and the medical center formed the team.

\section{Committee Plan for Course Development}

The team identified key issues to be addressed. These included determining what currently exists in the various curricula, the logistics of scheduling, the appropriate level of education needed by the students in different programs for course enrollment, course grading across academic programs, and program-specific curriculum committee approvals.

\section{Current Curricular Content}

The team first determined content breadth, depth, and scope of patient safety material already included in the curriculum of each of the health professions and other programs (Table 1). It was determined that all course offerings identified were integrated into other courses and were narrow in focus, specific to the discipline, and lacked foundational knowledge and theory specific to the sciences of safety or systems improvement. The committee concluded that a foundation course that included basic science of safety and its application in a patient-centered interdisciplinary approach would be of universal value to the students of all professional disciplines.

\section{Scheduling Logistics}

A substantial challenge for the team was to find a time and course model that took into consideration program calendars and curricular schedules in different programs. Eventually, a model that accommodated program variations emerged. The model proposed a 1-month elective at a time consistent with the medical school block curriculum (2

TABLE 1. Summary of Number of Course Content Offerings and Faculty Members in Health Sciences Interested in Patient Safety by Discipline

\begin{tabular}{|c|c|c|}
\hline Academic Program & $\begin{array}{c}\text { Do any of your programs offer dedicated course work in } \\
\text { some area of patient safety? }\end{array}$ & $\begin{array}{c}\text { Do any of the faculty members in your school have a high degree } \\
\text { of interest/expertise in aspects of patient safety? }\end{array}$ \\
\hline Nursing & No & 1 Faculty member \\
\hline Medicine & No & 2 Faculty members \\
\hline Pharmacy & 18 Courses have limited content & 9 Faculty members \\
\hline $\begin{array}{l}\text { Physical } \\
\text { therapy }\end{array}$ & 12 Courses have limited content & 1 Faculty member \\
\hline Law & No & No \\
\hline Social work & No & No \\
\hline $\begin{array}{l}\text { Occupational } \\
\text { therapy }\end{array}$ & 4 Courses have limited content & 3 Faculty members \\
\hline Dentistry & 3 Courses have limited content & 1 Faculty member \\
\hline
\end{tabular}


continuous blocks of 2-week duration). A survey across program curricula concluded that this could be accommodated by the other curricula except dentistry (Table 2). The first offering occurred in the semester of spring 2005.

\section{Student and Program Level Considerations}

What students and what level of education should this course be designed for? The committee recognized that students of all levels of education within the professional programs would likely have an interest and that the prior knowledge of students would vary by program. From the original survey about coursework, it was clear that no course or program offered a comprehensive, core, and foundational science knowledge-based course. The team decided to develop the course in a way that no prerequisites were required for students to enroll and that students at any level in the curriculum could participate.

\section{Course Grading Across Academic Programs}

The grading scale of each professional discipline was examined. Pharmacy, nursing, physical therapy, occupational therapy, and social work had similar grading scales. However, medicine and dentistry had pass/fail/honors grading scales. The associate deans for academic affairs from the different schools met to discuss an optimal approach to a grading scale. It was decided that the course would have its own grading scale. Schools that offered pass/fail/honors grading would equate the earned letter grade to pass or fail, with no honors offered.

\section{Program-specific Curriculum Committee Approval}

Once the grading issues were resolved, the next step was to present the course to the different curriculum chairs of each discipline and program and garner the appropriate approvals needed to offer the course to specific program students. This process went well, most likely because there was already wide-scale faculty representation and involvement in course development. The course was integrated into the registration process for students from different schools and programs.

\section{Faculty Development and Engagement}

The faculty were provided with core reference materials, so a common understanding and familiarity was developed. Because the faculty became more knowledgeable about the main content, the faculty members provided specialty reference material of relevance to their own disciplines. These materials were assembled and placed in a common location for use and also electronically stored on the library resource site for the class when determined appropriate. Each faculty member submitted a 1-paragraph biographical sketch of background relevant to patient care safety and wrote a personal story about patient safety relevant to their own experience. These stories were used as part of the teaching material.

\section{Development of the Interprofessional Course}

The faculty represented complimentary sets of expertise important to the knowledge foundation of patient safety. Key writings essential to the science of patient safety across the health professions were reviewed. Curriculum committee chairs conducted surveys of the patient safety content offered within each school. A theoretical framework incorporating interprofessional concepts of roles and communications using a patient-centered approach was conceptualized to design the knowledge foundation and application-oriented course that was level appropriate. The course was purposefully structured and leveled to serve as a prerequisite to additional courses with more in-depth approaches to specific and more specialized aspects of systems and patient safety within the different professions and disciplines. Eventually, the course would serve as the foundation knowledge in a spiral-based curriculum design. However, because the current state of curricular content and development related to patient safety is so underdeveloped among all professions, the placement of this content learning was less of an issue in the development. This will need to be a future consideration. Student learning outcomes for a 2credit elective course were developed. These course outcomes state that during and on completion of this course, students will be able to do the following:

1. define and apply the basic principles and tenets of patient safety;

2. value patient safety within the professional practice framework;

3. discuss a systems approach to patient safety at the individual, clinical microsystem, organizational, and social level;

4. develop interprofessional communication skills with the common language of patient safety; and

TABLE 2. Program Accommodation of Curricular Delivery Model Proposed by the Committee

\begin{tabular}{lcc}
\hline Professional School Disciplines & Specific Programs Within Discipline Considered & Program's Present Curriculum Can Accommodate This Elective \\
\hline Nursing & BS nursing and nurse practitioner & Yes \\
Medicine & Doctor of medicine & Yes \\
Pharmacy & Doctor of pharmacy & Yes \\
Physical therapy & Doctor of physical therapy & Yes \\
Law & Doctor of jurisprudence & Yes \\
Social work & Bachelors in social work & Yes \\
Occupational therapy & Doctor of occupational therapy & Yes \\
Dentistry & Doctor of dental sciences & No \\
\hline
\end{tabular}


5. identify tools health professionals need to work effectively within the health system to improve patient safety.

The team then developed a strategic approach to course structure and development. The course was planned to be interactive face to face, with web-based content support. The instructional framework is case based, emphasizes application, and is interactive in the classroom throughout the class time. The course was offered once a week for 3 hours during a 4-week period. Four content units corresponding to each week were developed by subgroups of the faculty team according to faculty expertise. These subgroups developed unit outcome objectives and mapped them to the overall course objectives. Within each unit, 2 cases were developed to apply safety theory in an interprofessional context. The 11 content units were taught for 4 weeks, with patient case studies integrated (Table 3).

\section{Course Materials}

Each week was organized into a standard format, including a pretest to be completed before each class session to encourage student preparation to engage in classroom learning experiences. Students received "full credit" for completing the pretests, no matter what the accuracy of their performance. Course content was presented using multiple media, including videotapes, PowerPoint presentations, and content chapters from the course textbook developed by the instructors of the course on patient safety. One of our instructors led a curricular mapping process, with the faculty instructors to map curricular objectives against the chapters. The content organization was refined, and the curricular chapters were finalized. Patient cases were structured to illustrate the science of safety and interprofessional safety principles. The patient study cases were then developed and mapped against the curricular chapters. Chapter objectives formed the basis of unit objectives for the course. The format for each chapter included personal stories about safety from the authors, patient cases, content, and discussion questions. The book is presently being considered for publication. The course was supported by a course Web site (http://chrp. creighton.edu) using Blackboard and a reserved reading site accessible through the health sciences library (http://www. ereserves.creighton.edu).

Students representing different disciplines were placed in groups to discuss and analyze the cases in interprofessional conversations. A second case was provided for individual student homework after each session. This second case provided the students an opportunity to practice the skills and use the knowledge acquired during the course session. The second case was turned in as homework and used as an indicator of student progress. Course materials were posted to the Blackboard course Web site for ready access.

\section{Library Resources}

A library resources site was built and made accessible through the Health Sciences Library to provide essential papers and sentinel works related to patient safety. This repository was used by the faculty for faculty development, as
TABLE 3. Course Content of "Interprofessional Education 410: Foundations in Patient Safety"

Course Week 1

Chapter 1. Key Concepts in Patient Safety. The purpose of this chapter is to provide the core theory and knowledge that all health professionals must have to minimally understand and practice using patient safety principles. This chapter provides the underpinnings of core knowledge to support the remaining chapters and case studies. Every chapter that follows will incorporate these safety principles.

Chapter 2. Keeping the Patient Safe (The patient-I never thought anything could go wrong). The purpose of this chapter is to understand safety from the individual patient point of view. The patient's experience with health care- a "safe journey" (no aviation pun intended) in their experiences with care providers, health care organizations, and their caretakers is studied.

Chapter 3. Safety Improvement in Professional Practice. The purpose of this chapter is to understand safety from the professional's point of view. Patient safety will be examined from the professional's role within the health care delivery system and their experiences with patients and their caretakers, other care providers, and the structure of their practice environment.

Case Session 1. Case-based studies applying content knowledge for sections 1 to 3 .

Course Week 2

Chapter 4. Safety Improvement in Systems. Health care delivery should be understood from a systems perspective. The purpose of this chapter is to understand patient safety in this context. How systems affect patient safety at the individual, microsystem, and macrosystem levels will be studied. Concrete examples that translate theory to every day experience are provided.

Chapter 5. Safety Improvement Is Achieved Within Organizations. The purpose of this chapter is to understand safety from an organizational perspective. Organizations affect health care delivery systems and how safety is prioritized and implemented. An understanding of organizations and how they affect individual patient safety is examined.

Chapter 6. Safety Improvement in Culture. The purpose of this chapter is to understand how culture affects patient safety. The culture within the health care delivery system is a driver of how safety is perceived and valued. The importance of leadership at the administrative and clinical interface is studied.

Case Session 2. Case-based studies applying content knowledge for sections 4 to 6 .

Course Week 3

Chapter 7. Why Things Go Wrong. The purpose of this chapter is to provide the fundamental knowledge about the science of errors. An understanding of the inherent nature of errors is needed to improve human performance and structure considerations in safety.

Chapter 8. What to Do When Things Go Wrong. The purpose of this chapter is to understand what to do when patient safety problems occur. The roles and responsibilities of health professionals, employers and health care organizations, and patients are described. The complexities of the interface between the "blame-free culture" and the concepts of accountability are explored.

Case Session 3: Case-based studies applying content knowledge for sections 7 to 8 .

Course Week 4

Chapter 9. Safe Patient Care Systems. The characteristics and practices of safe patient care systems are studied. The concepts of continuous improvement and quality management are described. The principles of patient safety described in chapter 1 are applied in the form of a model describing a safe patient care system. A doable criterion standard bestpractices approach is described. An emphasis on prevention of errors through systems improvement is a key concept emphasized.

Chapter 10. The Use of Evidence to Improve Safety. This chapter examines the concept of evidence because it is applied to patient safety. The need to expand the definition of evidence to include quasi-experimental and exploratory findings is discussed. Implications to patient safety as a result of evidence-based approaches are explored.

Chapter 11. How Professionals Can Make Things Better. The purpose of this chapter is to promote the responsibility of all participants in health care delivery toward improving patient safety.

Case Session 4. Case-based studies applying content knowledge for sections 9 to 11 . 
materials to support classroom sessions, and as a secondary source of materials for further student enrichment. Students were given a username and password to access this site.

\section{Course Promotion}

The course was promoted campuswide to both faculty and students by the distribution of a 1-page flyer to student and faculty mailboxes and electronically through E-mail distribution lists. The distribution was timed to coincide with faculty student advising for elective course offerings. A "questions and answers" document was also distributed widely to assist the campus faculty to counsel and advise students properly.

\section{Course Enrollment}

Thirty-one students enrolled in the course, with representation from the disciplines of nursing, occupational therapy, pharmacy, and physical therapy. Two medical students and 1 dental student initially enrolled and then dropped the course approximately 2 weeks before its initiation.

\section{Course Delivery}

Faculty implemented the course development plan. Course readings and competency testing, completed by students before class, allowed faculty to clarify misconceptions and advance the application of patient safety science during each session. Errors in patient safety were brought to the classroom through multimedia and paper cases, allowing students to reexamine the theory in the context of patientcentered care. Following the example of interdisciplinary teamwork modeled by the faculty present at each session, students were able to engage in interdisciplinary dialogue and problem solving, requiring them to apply the knowledge of patient safety science.

\section{Assessment of Student Performance}

Several tools were developed and used to assess student performance. A pretest provided an indication of the extent to which students were grasping the reading material before coming to class. All students but one completed the pretest before each week of class, indicating a commitment to engagement and readiness. This was important for the instructors to know to be able to anticipate the level of informed class participation related to the material. The individual case study over each weekly session was completed in small groups in class. The students completed 5 questions for discussion for each case session. A group recorder reported a summary of the discussion to the faculty members involved. Faculty rotated among the discussion groups, asking questions to guide the discussion when necessary and correcting any misperceptions and answering questions. This material was evaluated by faculty members for appropriate representation of knowledge on patient safety. A final comprehensive case examination was developed. Student performance was graded for level of understanding and application of safety theory. The final examination was constructed to assess overall mastery of the content knowledge of patient safety science.

\section{Evaluation of the Course}

An evaluation of the course was designed to assess the following: student's perceptions of value and importance; faculty assessment of student performance, course structure, course content, and methods of instructional delivery; overall participation of health sciences and health sciences-related students, and future course needs based on the first course offering.

An end-of-course 5-minute feedback was solicited from the students. The students were asked at the end of the last class session to provide a written response to the following: "Could you take a few minutes and provide us with any comments you want the instructors to know to help us understand the impact and value of this course?" This was an optional response sheet and did not request any personal identifiers. A final course evaluation survey was also conducted.

A "post first offering of the course" faculty meeting was held to evaluate the course structure, content, and methods of instructional delivery from the instructional faculty point of view. Student performance data were evaluated, and future course needs were generated based on this session.

\section{Second Offering of the Course}

The course was offered a second time in the spring semester of 2006. An analysis of the student participation from the first and second offering was conducted. Analysis of the actual number of students who elected to participate and the potential number of students by program that could participate based on planned program enrollment was also conducted. Logistics for growth in this course are being considered in future planning.

\section{RESULTS}

\section{Student Performance and Perceptions}

The results associated with the final case examination indicate that the student application abilities were fairly high (Table 4). Students experienced learning at the application level within the cognitive domain and at the valuing level within the affective domain. ${ }^{3,4}$ Student case study performance indicates that $77 \%$ of the students achieved at least a midlevel performance rating in all 4 areas of final case study application of theory to practice.

Student reflections at the end of the course provide evidence of how students relate the application of this knowledge to their professional behavior. The reflection comments also demonstrate the value the students place on this content. There are 31 enrollees, and 29 provided comment on the end-of-course 5-minute feedback. Theme analysis was used to understand the main viewpoints shared by the students immediately on completion of the course. Six central themes emerged:

- Students perceived that the course had a major impact on their learning. Students described that they learned a great deal of new content, most often identified as "medical errors" and the magnitude of the patient safety problem. The course was characterized as "eye opening" or "opened 
TABLE 4. Rubric for Evaluation of Student Level of Understanding and Application of Safety Theory to Final Examination Case and Distribution of Student Performance

\begin{tabular}{|c|c|c|c|c|c|c|}
\hline \multirow{2}{*}{$\begin{array}{l}\text { Safety Theory } \\
\text { Content Area } \\
\begin{array}{l}\text { Identification of } \\
\text { errors/problems }\end{array}\end{array}$} & \multicolumn{2}{|r|}{$\begin{array}{c}\text { No. of Students Who } \\
\text { Achieved the Highest } \\
\text { Performance Rating = 3, } \\
n(\%)\end{array}$} & \multicolumn{2}{|r|}{$\begin{array}{l}\text { No. of Students Who } \\
\text { Achieved the } \\
\text { Midlevel Performance } \\
\text { Rating }=2, n(\%)\end{array}$} & \multicolumn{2}{|r|}{$\begin{array}{l}\text { No. of Students Who } \\
\text { Achieved } \\
\text { the Lowest Performance } \\
\text { Rating }=1, n(\%)\end{array}$} \\
\hline & $27(87)$ & $\begin{array}{l}\text { All errors/problems } \\
\text { were correctly identified }\end{array}$ & $3(10)$ & $\begin{array}{l}\text { Most but not all errors/ } \\
\text { problems were } \\
\text { identified }\end{array}$ & $1(3)$ & $\begin{array}{l}\text { Errors/problems were not } \\
\text { identified; others were } \\
\text { incorrectly identified }\end{array}$ \\
\hline Evidence-based action & $24(77)$ & $\begin{array}{l}\text { Sound recommendations } \\
\text { for system improvement } \\
\text { with evidence-based rationale }\end{array}$ & $5(16)$ & $\begin{array}{l}\text { Most recommendations } \\
\text { were sound, without } \\
\text { rationale based on } \\
\text { evidence }\end{array}$ & $2(6)$ & $\begin{array}{l}\text { Lack of systems-oriented } \\
\text { recommendations; } \\
\text { poor rationale } \\
\text { for recommendations }\end{array}$ \\
\hline Personnel management & $19(61)$ & $\begin{array}{l}\text { Action taken with } \\
\text { individual includes } \\
\text { improving the system }\end{array}$ & $11(36)$ & $\begin{array}{c}\text { Action taken with individuals } \\
\text { in a manner consistent } \\
\text { with a culture of safety }\end{array}$ & $1(3)$ & $\begin{array}{l}\text { Punitive action taken } \\
\text { with individuals - not consistent } \\
\text { with a culture of safety }\end{array}$ \\
\hline $\begin{array}{l}\text { Evidence-based } \\
\text { decision making } \\
\text { with reference to } \\
\text { disclosure }\end{array}$ & $14(45)$ & $\begin{array}{l}\text { Evidence-based decision } \\
\text { making articulated with } \\
\text { understanding of } \\
\text { ramifications of disclosure }\end{array}$ & $14(45)$ & $\begin{array}{l}\text { Consideration of relevant } \\
\text { concepts of disclosure }\end{array}$ & $3(10)$ & $\begin{array}{l}\text { Poor clinical decision-making } \\
\text { process without } \\
\text { evidence to substantiate } \\
\text { conclusion }\end{array}$ \\
\hline
\end{tabular}

my eyes," "extremely enlightening," "thought provoking," "constructive," and "dose of reality."

- Interprofessional teaching and learning was integral to the course. The variety of fields represented by the professors was regarded as interesting and enjoyable. Several commented about the importance of law as a discipline important to the subject matter. "All of the disciplines are needed from the student body" was a representative comment in relation to discussions of safety problems and solutions. The absence of medical and dental students in the class roster held a negative meaning. One student explored this outside the classroom, with a physician who served as her clinical preceptor in a different course:

"I have learned a lot in this course_I really hope the IOM [Institute of Medicine] report will continue to propel all healthcare professionals forward to placing patient safety at an even higher priority than it has been before. I was talking to one of our clinic doctors who spent 8 years practicing in a foreign country - he said "things are so much better here than anywhere else." I mentioned the statistics about a jumbo jet crash every other day and its equivalency to the number of people who die from medical errors each year. He seemed surprised. I also mentioned the lack of medical students in the class and how disappointing it was. He laughed and said it's because we all know they don't make mistakes. He was joking but I hope that is not a philosophy still permeating the practice of medicine. I hope this change in looking at medical error will become the way it is. Meaning - a move from finger pointing - blame punishment toward a more productive approach of using error to learn and prevent more mistakes."

- Students learned a different way of thinking. "The class makes you think different, i.e., thinking about systems rather than individuals." Students identified with the nature of patient safety and errors in a highly personal way and related the systems approach to problem solving as a critical approach.

- Instructional design and active learning methods were useful to student learning. The use of preclass readings and pretests was perceived by the students as helping to prepare them for classroom discussion and complete readings ahead of time. This was regarded as a positive approach. Students appreciated the creation of a "discussion atmosphere" and an "interdisciplinary atmosphere" in class. The case studies were regarded as helpful to "visualizing problems" and to prompt interdisciplinary decision making and solutions. The use of videos was regarded as high impact by the students.

- Course content prepared students to solve problems for a future that was inevitable. Students regarded the content as relevant to their own future issues that each of them will be facing in health care. They stated the importance of being prepared to handle this by learning the solutions to dealing with unsafe practices and errors. Some indicated that this 
course experience directly contributed to essential professional development. Others described their lifelong intent to continue to study and learn in this area.

- Course content should be required by all health professions students. The overwhelming attitude that prevailed among student comments was the essential need for all health professionals to learn this content. Student comments that were made without leading questions or specific inquiry about mandatory offerings indicate their powerful beliefs about this:

"I honestly wish that everyone could take this course or at least be exposed to the issues. "'II think this is a good course for all students to take (perhaps as a first year requirement?), and I have learned a lot more than I expected in the last 4 weeks. "'I've enjoyed this class and think it should be a requirement for graduation. "'"Mostly I was surprised that a class like this is not...a) mandatory, b) longer, and c) already in place before the year. "'"I think this course should be required for all healthcare professionals. "'"I am so supportive of the objectives and purposes of this course that I am surprised it is not required for all health professions. "'II hope that this class becomes required in the future for ALL healthcare professions. "'II would recommend this course to everyone in a related field in hopes of having more health care professionals motivated toward patient safety. "'"I highly recommend that the university makes this course mandatory to everyone going into health care. In reality, the government should make this course a requirement at every 4 - and 2-year college. "'"I have really enjoyed this course. I would like to see it worked into the required curriculum. "'"This course has a lot of value. I think it should be required."

A final course evaluation was also conducted with the students after the final examination was completed. Table 5 displays the strength of the belief of students in the importance of this content area for learning within the health professions. Almost all students believe that the material is an essential core knowledge for all health professionals, and most believe that the course should be required for all health professionals.

Students were also asked to determine the extent to which they agreed with the impact of the course on their learning and abilities in relation to patient safety. Table 6 displays the results to 5 key questions.

Finally, student response to the final course evaluations indicated that $96 \%$ either strongly agree or agree that they can define and apply the basic principles and tenets of patient safety, including identification of tools needed to work effectively within the health system to improve safety. Furthermore, $100 \%$ strongly agree or agree that they value patient safety as a professional practice framework.

Triangulation of student comments, final course evaluation, and student performance evaluations were performed, whenever possible, to reveal key findings. Students believe this course content is essential and should be the required core knowledge for all health professions students. The final course assessment revealed that $87 \%$ of the students believe that the material taught in the course is core knowledge and that it is essential that it be learned by all health professionals, and $74 \%$ believe that this course should be required for all health professions students. Students were proactive in their beliefs about this content being required and essential to health professions training.

\section{Course Structure, Content, and Delivery}

The faculty instructional group reviewed the course structure, student performance outcomes, and experiences of the faculty and students. Course content and delivery were determined a success based on student performance and student and faculty perceptions. The major problem that emerged was the finding that more students from other disciplines did not enroll. This problem was attributed to structure. The professional cultures and curricular philosophy vary for each program of study. Some program cultures are less engaged with patient safety as a priority compared with others. Some program curricular philosophies are open to elective education, and others are not. The practical aspects of scheduling the classroom opportunity also became evident for the medical and dental school programs. Finally, students in the pharmacy school program who were enrolled in the distance education degree pathway were not able to enroll and participate unless they were willing or able to travel to campus and participate in the 4 on-site classroom sessions for the course.

\section{Future Course Needs Based on the First Course Offering}

Course content and delivery remained unchanged after discussing the spring 2005 first-time course offering experience. Three substantive issues emerged. The first was the need to create awareness of the course opportunity to health sciences students. The second was the direct scheduling problem that existed with the School of Dentistry program 
TABLE 5. General Evaluation of Course Offering and Content $(n=30)$

and the structure problem that existed with the School of Medicine curriculum. The third was the need to evaluate how to offer the course for distance education opportunities while retaining the interprofessional relationship skills component of the coursework. This is built on direct interaction between students during classroom-based minilecture question-andanswer series, class discussions, and interprofessional small group case studies.

Awareness was tackled first. A promotion effort was developed whereby the primary course coordinator developed discipline-specific informational letters informing the students within that disciplinary program about the course availability. The letters were signed by the faculty who taught in the course that were representatives of that discipline and circulated throughout the student classes for each discipline.

The scheduling problem with the School of Dentistry was explored with the Dean. Discussions are progressing to find a workable solution. The culture of dentistry does not seem ready or proactively interested in interprofessional engagement compared with most of the other disciplines involved in the course offering. The curricular structure is also most different from the other disciplines in that the elective offerings are offered in short and specific miniofferings, of which, the dental students may choose from approximately 100 options. This makes the participation in a larger and lengthy course on patient safety less familiar and less compatible with the elective options these students are presented with.

The School of Medicine was cooperative but challenged to find a way to incorporate the availability of this class into the curriculum. A creative approach to integrating this course into the medical school curriculum as an elective option during the clinical minielective offerings was designed by the medical school faculty and incorporated. This has opened the opportunity to directly promote the course to medical students and encourage their engagement.

The area of distance education offerings will be dealt with in the coming year. The challenge of creating an interprofessional experience without the classroom engagement is substantive. A focused exploration into this challenge is planned.

\section{Participation of Health Sciences and Related Students}

An analysis of the student participation from the first and second offering reveals that the enrollment rose from 31 students in 4 programs to 78 students representing 7 programs. This increase in student elective enrollment is strongly suggestive of a future increase in the participation at the elective level. In addition, the newest member of our patient safety faculty is the chair of the Health Care Program at the Werner Institute for Negotiation and Dispute Resolution within Creighton. After a pilot experience of 2 law students taking the course during the second offering, the newly formed master's degree offered at the institute has identified this course as a degree-satisfying option in the health care track.

Analysis of the actual number of students who elected to participate and the potential number of students by program that could participate based on planned program enrollment was also conducted. This analysis is shown in Table 7. The first time the course was offered, a potential of

TABLE 6. Student Evaluation of Impact of Course on Student Learning and Abilities $(n=30)^{*}$

\begin{tabular}{|c|c|c|c|c|c|}
\hline As a result of taking this course: & $\begin{array}{l}\text { Strongly } \\
\text { Agree }\end{array}$ & Agree & Neutral & Disagree & $\begin{array}{l}\text { Strongly } \\
\text { Disagree }\end{array}$ \\
\hline I can define and apply the basic principles and tenets of patient safety & 44 & 48 & 0 & 4 & 0 \\
\hline I value patient safety as a professional practice framework & 78 & 17 & 0 & 0 & 0 \\
\hline $\begin{array}{l}\text { I am able to discuss a systems approach to patient safety at the individual, clinical microsystem, } \\
\text { organizational, and social level }\end{array}$ & 26 & 65 & 4 & 0 & 0 \\
\hline $\begin{array}{l}\text { I have developed interprofessional communication skills with the common language of patient } \\
\text { safety }\end{array}$ & 39 & 39 & 13 & 4 & 0 \\
\hline $\begin{array}{l}\text { I can identify tools health professionals need to work effectively within the health system to effect } \\
\text { improvement in patient safety }\end{array}$ & 48 & 44 & 0 & 4 & 0 \\
\hline
\end{tabular}


TABLE 7. Actual Versus Potential Student Enrollment by Discipline Specific Program

\begin{tabular}{|c|c|c|c|c|c|c|}
\hline & \multicolumn{3}{|r|}{2004} & \multicolumn{3}{|r|}{2005} \\
\hline & Actual, $n$ & Potential, $n$ & Percentage of Potential Enrolled, \% & Actual, $n$ & Potential, $n$ & Percentage of Potential Enrolled, \% \\
\hline Nursing* & 4 & 16 & 25 & 2 & 14 & 14 \\
\hline Medicine $\dagger$ & 0 & 108 & 0 & 3 & 105 & 3 \\
\hline Pharmacy! & 25 & 220 & 11 & 63 & 220 & 29 \\
\hline Physical therapy§ & 1 & 50 & 2 & 11 & 50 & 22 \\
\hline Law $\|$ & 0 & 168 & 0 & 2 & 152 & 1 \\
\hline Social work & 0 & 7 & 0 & 2 & 10 & 20 \\
\hline Occupational therapy** & 1 & 39 & 3 & 0 & 33 & 0 \\
\hline Dentistry ${ }^{\dagger} \dagger$ & 0 & 86 & 0 & 0 & 85 & 0 \\
\hline Total & 31 & 694 & 5 & 83 & 669 & 13 \\
\hline $\begin{array}{l}\text { *Course available to nur } \\
\text { recognized in the degree cur } \\
\dagger \text { Course available as a } n \\
\text { †Course available to doc } \\
\text { There are } 10 \text { credit hours of } \\
\text { §Only } 1 \text { of } 3 \text { academic } y \\
\| \text { Two law students were } \\
\text { resolution curriculum. } \\
\text { TCourse available to stu } \\
* * \text { No elective hours are } \\
\text { primary curricular issues we } \\
\dagger \text { Only } 1 \text { academic year } \\
\text { enrollment of students. }\end{array}$ & $\begin{array}{l}\text { sing students } \\
\text { riculum of ba } \\
\text { niniclinical el } \\
\text { tor of pharmac } \\
\text { elective cour } \\
\text { years is practi } \\
\text { auditors in th } \\
\text { dents in the b } \\
\text { built into the } \\
\text { re resolved. } \\
\text { of practical s }\end{array}$ & $\begin{array}{l}\text { in bachelor of sci } \\
\text { chelor of science } \\
\text { ective, with med } \\
\text { cy students in tra } \\
\text { sework recogniz } \\
\text { cal for students } \\
\text { e course. Experi } \\
\text { achelor's degree } \\
\text { curricular mode } \\
\text { tudy in curriculu }\end{array}$ & $\begin{array}{l}\text { ience in nursing, accelerated degree, and master } \\
\text { e in nursing program. } \\
\text { lical students using two of the } 2 \text {-week blocks s } \\
\text { ditional campus pathway. There is a distance pa } \\
\text { ed in the degree curriculum. } \\
\text { to enroll. No elective hours are built into the c } \\
\text { ence resulted in course being available to law s } \\
\text { program. } \\
\text { el. The program initiated a curricular reform p } \\
\text { Im. Structure of electives is incompatible with }\end{array}$ & $\begin{array}{l}\text { of science in } \\
\text { cheduled at } t \\
\text { thway; studen } \\
\text { urricular mod } \\
\text { students as eli } \\
\text { rocess and p } \\
\text { the course. A }\end{array}$ & $\begin{array}{l}\text { nursing program } \\
\text { hat time. } \\
\text { tts can enroll but } \\
\text { del. } \\
\text { igible course opti } \\
\text { laced a moratorit } \\
\text { process is in pla }\end{array}$ & $\begin{array}{l}\text { Is. Only } 3 \text { credit hours of elective coursework } \\
\text { must get to campus for the } 4 \text { in-class sessions. } \\
\text { ion in new masters in negotiation and dispute } \\
\text { um on students taking electives, whereas the } \\
\text { ce to dermine alternative approaches to the }\end{array}$ \\
\hline
\end{tabular}

694 students across the disciplines were eligible to take the course based on the restrictions and requirements of their respective programs. The student population enrolled represents $5 \%$ of the potential for the first course offering. The second course offering enrolled $13 \%$ of the total potential. We expect that the next offering will increase further. Logistics for growth in this course are being considered in future planning.

\section{DISCUSSION}

A variety of curricula that focuses on the aspects of patient safety has been described in the literature. Most of these curricula are designed for postgraduate professionals, such as physicians and medical residents, nurses, organizational leaders, faculty leaders, and graduate students. ${ }^{5-8}$ Curricula have also been designed to focus on specific content areas including the following: Joint Commission National Patient Safety Goals, reporting of adverse drug reaction, human factors, minimizing risks of falls and injuries and minimizing infections, and key concepts in ambulatory care safety. $^{9-14}$

The broad array of health professions and health-related professions (social work and law) programs at Creighton University is a major advantage in the development of interprofessional courses in general, specifically in developing and offering a course of the breadth and magnitude of the Foundations of Patient Safety course.

Why did the faculty stay engaged? We believe that this occurred because of both individual interest and support of organizational level. The course coordinator visited each faculty member to discuss interests and commitment required. Each was asked why they were interested. Almost everyone described a personal story involving an error or injury to someone else. It is probably the intrinsic personal experience that has sustained the engagement of the faculty.

Organizational infrastructure at an organizationally high level (Health Sciences Office of Interprofessional Education at Creighton) was an important contribution to support the development of such an interprofessional course. The institutional recognition of the essential importance of interprofessional education catalyzed the cross collaboration between health professions and other schools and programs on campus and provided a structure to maintain communications. Even with these 2 factors present, the course leader had to remain vigilant to overcome barriers and use creative 'workarounds' to build bridges between academic silos evident in course credit, teaching load, academic recognition, and ownership by the faculties of the respective schools.

Why did the various programs approve and support the offering of this patient safety course for their respective students? It is our belief that the engagement of the faculty across the disciplines, as advocates for this course of study, was the key to the individual program recognition and support. These individuals contributed through ongoing communication and support of the effort to bring this course to a realistic level of acceptance. They also broadcast their enthusiasm for this important effort to others, generating awareness and knowledge of this opportunity.

Interprofessional case studies were particularly useful because the safety sciences were discussed in a systems context. It was evident in the student comments how different professionally unique knowledge and context influenced the groups' ability to actually see the "invisible" human system that exists in the patient care delivery system.

One area of student dissatisfaction is the fact that no medical, dental, or law students were involved initially. 
Successful integration of the law and medical student leadership and students has been initiated. We expect that the third offering will advance this engagement further through refining the commitment and communication of the faculty and students to this initiative. We are uncertain if the dental student involvement will be resolved by the third offering but continue to work toward that goal. The next strategy being used is to invite school deans, university vice presidents, and student organization leaders to the course offering to heighten the awareness of our leadership. We believe that it is inevitable that this area of study will become required within the health care-related programs of study. Our plan is to resolve the dental student curricular conflict this coming year, develop a pilot for the web delivery model of the course, and repeat the promotion and dissemination for enrollment strategy that was conducted for the second offering. We will engage the academic leadership to discuss curricular requirements for the course after assessing the outcome of the third offering to discuss the feasibility and the need for required adoption of this course content throughout the healthrelated disciplines.

\section{Considerations for Implementation of a Foundational Patient Safety Course}

Just as is needed in the practice environment, a champion who leads the engagement of faculty and forward movement of the course development is an essential step to success in such a complex and wide-reaching endeavor. Organizational infrastructure at a higher level within the university was a large contributor to the creation of cultural awareness of the importance of this course of study within the university. If such a structure is not present, the cultural awareness issue must be addressed. Before considering such an offering, assembling the faculty resources available who are interested and can commit to such a venture should occur. Planning from this group should include an analysis of the existing resources and curricular effort among different academic programs within the university. Limitations must be evaluated and considered in the approach to creating the offering. Key limitations that must be addressed include the following: curricular culture, philosophy of curriculum of study for each discipline-specific program, faculty awareness and attitudes toward this material, practical aspects of available curricular time across programs, varying requirements for curriculum committee approvals by programs, cross-program course scheduling, and technical variation for student registration and enrollment processes. The champion must continue to nurture the interprofessional faculty relationships and logistical steps. Aggressive promotion of the course availability is important to the cultural formation and awareness of faculty and students. Promotion of the course and its content and value among the students and faculty members must continue while the course is being established across the disciplines of study.

\section{CONCLUSIONS}

Continued promotion of this course to the full compliment of health sciences disciplines and related fields is a necessary step to further the course integration into the different program curriculum. This course is a "first" in the nation. Although several schools have introduced patient safety courses into professional curriculum, the greatest degree of professional integration achieved, to our knowledge, has occurred between 2 disciplines: pharmacy and nursing. The engagement and involvement of this breadth of faculty and students are not paralleled to date. The course description and the approach to integration and adoption by faculty and students described here may serve as a model for others considering the adoption of a similar course of study.

\section{REFERENCES}

1. Kohn LT, Corrigan JM, Donaldson MS. To Err is Human: Building a Safer Health System. Washington, DC: Institute of Medicine, 2000.

2. Greiner AC, Knebel E, eds. Health Professions Education, A Bridge to Quality. Washington, DC: Institute of Medicine of the National Academies, The National Academies Press; 2003.

3. Bloom BS, ed. Taxonomy of Educational Objectives: Book 1, Cognitive Domain. New York, NY: Longman; 1956.

4. Krathwohl DR, Bloom BS, Masia BB, eds. Taxonomy of Educational Objectives: Book 2, Affective domain. New York, NY: Longman; 1964.

5. Hendee WR, Keating-Christensen CMA, Loh YH. Development of a Patient Safety Web-based Education Curriculum for Physicians, Nurses, and Patients. J Patient Safety. 2005;1:90-99.

6. Barach PB. Patient safety curriculum. Acad Med. 2000;75:551-552.

7. Mitchell PH, Robins LS, Schaad D. Creating a curriculum for training health profession faculty leaders. In: Henrikson K, Battles JB, Marks ES, et al., eds. AHRQ Advances in Patient Safety: From Research to Implementation. Rockville, MD: Agency for Healthcare Research and Quality, Feb 2005:299-312.

8. Karsh BT, Carayon P, Maureen S, et al. The University of WisconsinMadison Multidisciplinary Graduate Certificate in Patient Safety. In: Henrikson K, Battles JB, Marks ES, et al., eds. AHRQ Advances in Patient Safety: From Research to Implementation, Feb 2005:269-281.

9. Jaghab D, Kostner L, Halliday A. Using a Distance-Learning Program to Educate Staff on the Joint Commission National Patient Safety. Jt Comm J Qual Saf. 2004;12:671-675.

10. Rosebrough CJ, Tsong Y, Zhou F, et al. Improving the quality of adverse drug reaction reporting by 4 th year medical students. Pharmacoepidemiol Drug Saf. 2003;12:97-101.

11. Glavin RJ, Maran NJ. Integrating human factors into the medical curriculum. Med Educ. 2003;37:59-64.

12. Benezo C, Gaudy D, White TM. Keeping each patient safe: quality safety teaching/learning packets. Jt Comm J Qual Saf. 2004;30:676-680.

13. Donaldson NE, Plank RK, Williamson A, et al. Expediting clinician adoption of safety practices: the UCSF Venous Access Patient Safety Interdisciplinary Project. In: Henrikson K, Battles JB, Marks ES, eds. AHRQ Advances in Patient Safety: From Research to Implementation, Feb 2005:283-297.

14. Mottur-Pilson C. An ambulatory care curriculum for advancing patient safety. In: Henrikson K, Battles JB, Marks ES, et al., eds. $A H R Q$ Advances in Patient Safety: From Research to Implementation, Feb 2005:313-323. 